NBER WORKING PAPER SERIES

\title{
REAL OPTIONS IN A DYNAMIC AGENCY MODEL, WITH APPLICATIONS TO FINANCIAL DEVELOPMENT, IPOS, AND BUSINESS RISK
}

\author{
Thomas Philippon \\ Yuliy Sannikov \\ Working Paper 13584 \\ http://www.nber.org/papers/w13584
NATIONAL BUREAU OF ECONOMIC RESEARCH
1050 Massachusetts Avenue
Cambridge, MA 02138
November 2007

We are grateful to Steven Davis, John Haltiwanger, Ron Jarmin and Javier Miranda for providing us with data, and to Patrick Kehoe, Alexander Ljungqvist, Fabrizio Perri and Jean-Charles Rochet, as well as seminar participants at NYU, Princeton and the Minnesota Workshop in Macroeconomic Theory for their comments. The views expressed herein are those of the author(s) and do not necessarily reflect the views of the National Bureau of Economic Research.

(C) 2007 by Thomas Philippon and Yuliy Sannikov. All rights reserved. Short sections of text, not to exceed two paragraphs, may be quoted without explicit permission provided that full credit, including (C) notice, is given to the source. 
Real Options in a Dynamic Agency Model, with Applications to Financial Development, IPOs, and Business Risk

Thomas Philippon and Yuliy Sannikov

NBER Working Paper No. 13584

November 2007

JEL No. D82,D86,D92,E22,G31,G32,G33

\section{ABSTRACT}

We study investment options in a dynamic agency model. Moral hazard creates an option to wait and agency conflicts affect the timing of investment. The model sheds light, theoretically and quantitatively, on the evolution of firms' dynamics, in particular the decline of the failure rate and the decrease in the age of IPOs.

Thomas Philippon

NYU Stern School of Business

Department of Finance

44 West 4th Street, Suite 9-190

New York, NY 10012-1126

and NBER

tphilipp@stern.nyu.edu

Yuliy Sannikov

NYU Stern School of Business

Department of Finance

44 West 4th Street, Suite 9-190

New York, NY 10012-1126

sannikov@gmail.com 
"Indivisibilities, fixed costs, and irreversibility are not the only frictions to capital adjustments. Financial frictions - which are in many ways leveraged by the above frictions - are central to the investment literature." Ricardo J. Caballero. ${ }^{1}$

We study the optimal timing and financing of large, irreversible investments in the presence of moral hazard. These two issues, timing and financing, have typically been studied separately. The real option literature, well summarized in Dixit and Pindyck (1994), focuses on the timing of irreversible investments. The corporate finance literature analyzes financing issues when the lender and the borrower do not the share the same information set, ex-ante or ex-post. These two literatures, however, are largely disjoint. We argue that it is both possible and fruitful to bring them together.

We develop a dynamic agency model in which the firm can be scaled up by paying a fixed cost. We formulate the problem in continuous time and we obtain explicit comparative statics regarding the probability of failure and the timing of investment. We show theoretically that, when financial markets improve - with better property rights, disclosure and enforcement - firms are less likely to fail and more likely to exercise the growth option. We then use our model to study quantitatively the evolutions of firms' dynamics over the past 50 years, in particular the decline of failure rates (Davis, Haltiwanger, Jarmin, and Miranda (2006)), and the decrease in the age at which firms go public (Jovanovic and Rousseau (2001)).

The real option and agency literatures have remained separate mainly because of technical difficulties. For instance, real options are best understood in a continuous time framework (Dixit and Pindyck (1994), Caballero and Engle (1999)), while agency problems have traditionally been studied in discrete time. Discrete-time agency problems include papers on optimal Venture Capital contracts such as Admati and Pfleiderer (1994), Chemmanur and Fulghieri (1999), Casamatta (2003) and Schmidt (2003). This literature helps us understand the theoretical underpinnings of observed contracts, and in particular the role of asymmetric information and moral hazard between the entrepreneur and the $\mathrm{VC}$, as well as between the VC and the outside investors. These models, however, use very stylized frameworks, typically with two or three periods, that do not encompass the standard models of

\footnotetext{
${ }^{1}$ Aggregate Investment: Lessons from the Previous Millenium, AEA Session. In Memoriam: Robert Eisner. January 8, 2000.
} 
investment used elsewhere in economics. Two notable exceptions are DeMarzo and Fishman (2007) and DeMarzo, Fishman, He, and Wang (2007), who combine investment and agency issues. These models, however, do not capture lumpy investments and real options.

There is, on the other hand, a literature that looks at IPOs from the perspective of classical investment theory, like Jovanovic and Rousseau (2001) and Pastor and Veronesi (2005). These papers bring insights on IPO waves and valuations, but they do not deal with incentives contracts. Yet, it is widely acknowledged that incentives and information issues are of first order practical importance. Ideally, one would like to include an option to invest into the multi-period agency models of DeMarzo and Fishman (2004), Clementi and Hopenhayn (2006) or Albuquerque and Hopenhayn (2004), but discrete-time agency models are already quite complex. ${ }^{2}$

This paper makes two contributions to the literature: it provides a methodology and it suggests an interpretation for a set of stylized facts. We are able to study lumpy investment in a dynamic agency model thanks to the continuous-time formulation of DeMarzo and Sannikov (2006). ${ }^{3}$ With this methodology, we obtain analytical comparative statics despite the complexity of the problem. Technically, we derive our results from a system of scaled differential equations. These tools turn out to be quite powerful and could be fruitfully applied to other economic problems.

The main difference between our model and the classic real option model comes from the value of the option to wait. In the classic model, the value of the firm varies over time because of persistent shocks to its profit rate, and once the value crosses a given threshold, it becomes optimal to scale up. In our model, by contrast, cash flows are i.i.d. so that, without moral hazard, the firm would either upgrade immediately, or it would never do so. The option value comes entirely from the history dependence of the optimal contract. That is, the upgrade option becomes valuable only when the agent's future expected payoff is sufficiently high and the threat of liquidation sufficiently remote.

We then use our model to study firm dynamics. In doing so, we interpret the first large investment in the life cycle of the firm as its IPO, which is consistent with the empirical

\footnotetext{
${ }^{2}$ See also Quadrini (2004), who studies the case where contracts are renegotiation-proof and Cooley, Marimon, and Quadrini (2004) for a general equilibrium model with dynamic contracts and limited enforcement.

${ }^{3}$ Biais, Mariotti, Plantin, and Rochet (2007) show that the optimal contract of DeMarzo and Sannikov (2006) arises in the limit of discrete-time models that converge to continuous time.
} 
evidence and is also the interpretation in Pastor and Veronesi (2005). We perform a complete calibration of the model using information on investment dynamics, assets prices and actual VC contracts. The model allows us to quantify - for the first time to the best of our knowledge - the consequences of moral hazard, in particular for business failures and the timing of IPOs. Our quantitative model also sheds light on a set of recent stylized facts. Using the Longitudinal Business Database, Davis, Haltiwanger, Jarmin, and Miranda (2006) document a decline in the failure rate, especially among private businesses, while Fink, Fink, Grullon, and Weston (2005) document a decline in the age at which firms go public. In our model, both facts can be explained by improvement in financial contracts. Our model can also account for the increase in volatility among public firms (Campbell, Lettau, Malkiel, and Xu (2001), Comin and Philippon (2005)) because most of the observed trend in idiosyncratic risk is due to the fact that recent cohorts are made of younger and more volatile firms (Fink, Fink, Grullon, and Weston (2005)). ${ }^{4}$

The rest of the paper is organized as follows. In section 1, we present our model and we discuss in more details how it relates to the literature. In section 2 , we characterize the optimal contract. In section 3, we derive the predictions of the model regarding the age-profile of firm volatility and we show how financial development affects IPO age, exit rates, and volatilities. In section 4, we present a calibration of the model.

\section{The Model}

To achieve the goals presented in the introduction, the model must be dynamic, include asymmetric information, allow for endogenous exit, and capture at least some of the key features of IPOs. The challenge is therefore to keep the analysis tractable and transparent. For this reason, we choose to work in a continuous time framework. Continuous time models are more difficult, and less well-known to many economists, than discrete time models, but we hope that the ability to obtain clean, analytical results justifies our approach.

\footnotetext{
${ }^{4}$ Using the idiosyncratic component of stock returns, Campbell, Lettau, Malkiel, and Xu (2001) document a rise in volatility among publicly traded companies. Comin and Philippon (2005) show that the rise in idiosyncratic risk is also apparent in the growth rates of assets, employment, cash flows and sales. This result does not extend to privately held companies, however. Using the Longitudinal Business Database, Davis, Haltiwanger, Jarmin, and Miranda (2006) show that volatility has decreased substantially among private businesses, mostly because of a decline in the failure rate.
} 


\subsection{Technology and Preferences}

A firm is run by an entrepreneur/manager and financed by an outside investor. The manager and the investor are both risk neutral. The investor discounts future cash flows at the market rate $r$, and the manager discounts her future consumption at rate $\gamma>r$. Setting up the firm requires a fixed initial investment of $I$ at time 0 . The manager has limited wealth and she contracts with the outside investor, who can pay the initial investment, cover the firm's losses and provide funding to upgrade the firm's capital.

Let $X_{t}$ denote the cumulative cash flows produced by the firm up to time $t$. The incremental cash flows $d X_{t}$ expected between $t$ and $t+d t$ depend on the scale of the firm $\tilde{\mu}_{t}$ and the action of the manager, $\alpha_{t}$ :

$$
E\left[d X_{t}\right]=\left(\tilde{\mu}_{t}-\alpha_{t}\right) d t
$$

The scale of the firm can take two values. After the initial investment, the scale is $\tilde{\mu}_{t}=\mu$. At any point in time, the firm has the option to upgrade its capital stock for a cost $K>0$. The upgrade increases the scale of the firm to $\tilde{\mu}_{t}=\bar{\mu}$. We assume that $\bar{\mu}-\mu>r K$ so that the capital upgrade is potentially profitable from the point of view of investors. We shall later explain how we can interpret the capital upgrade as an initial public offering (IPO). The manager gets a benefit at the rate of $\lambda \alpha_{t}$ by taking a hidden action $\alpha_{t} \in[0, \infty)$, where $\lambda \in(0,1)$. We can interpret $\alpha_{t}$ as a reduction in effort, or as diversion of cash flows for private benefits.

Note that, conditional on scale and managerial effort, the expected cash flows are constant. The usual real option trade-off therefore does not arise in our model. Without asymmetric information, it would be optimal to upgrade immediately.

\subsection{Information}

Information is asymmetric, because the investor does not observe the action $\alpha_{t}$ of the manager. Rather, the investor observes a signal $\Omega_{t}$ that evolves according to:

$$
d \Omega_{t}=-\alpha_{t} d t+\sigma d Z_{t} .
$$

The signal $\Omega_{t}$ summarizes all the information of the investor regarding the action of the manager. In particular, we assume that $\Omega_{t}$ is a sufficient statistic for $\alpha_{t}$ given $X_{t}$. Therefore, 
without loss of generality, the optimal contract depends only on the process $\Omega$. A particular case of our setup is when $\Omega$ and $X$ contain the same information, i.e., when the principal only observes the cash flows. This is the case that is most often studied in the literature. This is only a particular case, however, and while it make sense for mature companies, it does not make sense for young firms that do not even produce cash flows. Venture Capitalists certainly observe more than the current profits of the firm in which they invest.

In our model, the degree of moral hazard depends on two parameters: $\sigma$ and $\lambda$. In fact, we will later show that only the product $\lambda \sigma$ matters: when it goes to zero, the model converges to the case of full information. More generally, we can think of improvements in financial contracts as a decrease in $\sigma$ or in $\lambda$. A decrease in $\sigma$ captures better disclosure of information, while a decrease in $\lambda$ captures better protection of property rights.

\subsection{Contracting}

To finance the firm, investors can write fully contingent dynamic contracts that specify how the agent's cumulative compensation $C_{t}$, the upgrade time $\tau_{K}$ and the time when the agent is fired $\tau_{L}$ depend on the path of $\left\{\Omega_{t}\right\}$. If the manager is fired, the firm is worth $L<\mu / r$ before the upgrade, and $\bar{L}<\bar{\mu} / r$ after the upgrade. $L$ and $\bar{L}$ could capture either liquidations values, or values under a new management, net of the replacement cost, without loss of generality. The outside value of the manager upon liquidation is denoted $W_{L}$.

A contract $\left(\tau_{L}, \tau_{K},\left\{C_{t}, t \leq \tau_{L}\right\}\right)$ is optimal if it maximizes the principal's profit

$$
E\left[\begin{array}{c}
\int_{0}^{\min \left(\tau_{L}, \tau_{K}\right)} e^{-r t}\left(\mu d t-d C_{t}\right)+1_{\tau_{L}<\tau_{K}} L e^{-r \tau_{L}}+ \\
1_{\tau_{L}>\tau_{K}}\left(\int_{\tau_{K}}^{\tau_{L}} e^{-r t}\left(\bar{\mu} d t-d C_{t}\right)+e^{-r \tau_{L}} \bar{L}-e^{-r \tau_{K}} K\right)
\end{array}\right]
$$

subject to delivering to the agent a payoff of $W_{0}$, determined by the relative bargaining powers of the agent and the principal, i.e.

$$
W_{0}=E\left[\int_{0}^{\tau_{L}} e^{-\gamma t} d C_{t}+W_{L} e^{-\gamma \tau_{L}}\right], \quad \text { given actions }\left\{\alpha_{\mathrm{t}}=0\right\},
$$

and providing the agent with incentives to take action $\alpha_{t}=0$,

$$
W_{0} \geq E\left[\int_{0}^{\tau_{L}} e^{-\gamma t}\left(d C_{t}+\lambda \alpha_{t} d t\right)+W_{L} e^{-\gamma \tau_{L}}\right], \quad \text { given any actions }\left\{\alpha_{\mathrm{t}} \geq 0\right\} .
$$

In the optimal contract the agent's action is $\alpha_{t}=0$ at all times. Indeed, because $\lambda<1$, it is always cheaper to pay the agent cash directly rather than let him get utility indirectly by reducing the firm's cash flows. 


\subsection{Discussion and relation to the literature}

The optimal contracting approach abstracts from the details of contractual implementation. Those details can be different depending on the institutional environment, the level of financial development, and standards within an industry. Our approach is based on the premise that the contracting parties have the interest to put together the best possible contract given the tools available to them, to approximate the optimal contract. Thus, the optimal contracting theory should deliver reasonable predictions about the timing of investment and the growth of value across contractual environments. DeMarzo and Sannikov (2006), Sannikov (2007a), Biais, Mariotti, Plantin, and Rochet (2007) and Piskorski and Tchistyi (2006) give examples how optimal contracts can be implemented using standard securities in various institutional environments. DeMarzo and Fishman (2004) focus on how the optimal contract can be implemented using simple financial instruments, such as a credit line and long term debt. In Clementi and Hopenhayn (2006), the output of the firm can be adjusted every period and production is typically below the first best while the entrepreneur repays all the cash flows and incentives are provided through continuation values. DeMarzo and Fishman (2007) study investment in dynamic agency models. They show that a positive correlation between cash flows and investment, with higher sensitivity for small firms, as well as serial correlation in investment follow from simple properties satisfied by a large class of agency problems.

Besides real options, IPOs and dynamic agency contracts, our paper is also related to the literature on financial development. In our model, financial development is synonymous with better monitoring, better property rights, better enforcement or better financial information. Stulz (2005) argues that this view is consistent with much recent evidence.

\subsection{Interpretation of the Upgrade as an IPO}

We want to interpret the upgrade as an IPO, but we must acknowledge that the model does not capture some financial features of IPOs. In reality, IPOs allow (partial) exit by the initial investors and result in more dispersion of ownership. Chemmanur and Fulghieri (1999) model the costs and benefits of ownership dispersion. We cannot address this issue because it does not matter in our model whether the capital upgrade is financed by the initial investor (the principal) or by new outside investors. To capture these features, we would 
need to introduce different classes of investors and another layer of moral hazard to justify the initial concentration of ownership. We abstract from these issues in order to keep the model as tractable and transparent as possible. One way to gauge the relative importance of exit as a motivation for IPOs is to look at the relative issuances of primary and secondary shares. Primary shares are newly created shares while secondary shares are existing shares held by pre-IPO shareholders. One cannot exit by selling primary shares; anyone exiting would have to sell secondary shares. Kim and Weisbach (2007) show that roughly $80 \%$ of the proceeds from IPOs come from primary shares. They also show that over a three year period following the IPO, $61 \%$ of the proceeds are used to increase R\&D spending, and $22 \%$ are used to increase capital expenditures. Raising capital for productive investment therefore seems to be an important aspect of IPOs, and, given the focus of our paper, we believe that it is reasonable to focus on the investment aspect of IPOs rather than on the change in the ownership structure. Other theories and important facts, most notably the issues of underpricing and market timing, are reviewed in Jenkinson and Ljungqvist (2001) and Ritter and Welch (2002).

It may also appear objectionable that our contract specifies all contingencies, both before and after the IPO, whereas in practice VC contracts before the IPO are separate from the contracts with equity-holders after the IPO. This objection is resolved by observing that the optimal contract can be implemented simply by specifying the agent's compensation $\left\{C_{t}, t \leq \min \left(\tau_{L}, \tau_{K}\right)\right\}$ before the IPO and the agent's payoff $W_{\tau_{K}}$ at the time of the IPO. ${ }^{5}$ Then at time $\tau_{K}$, the manager and new equity-holders have incentives to write the optimal continuation contract. This recontracting at time $\tau_{K}$ implements the optimal fully contingent contract ex-ante. In this argument it is important that, although our optimal contract is not fully renegotiation-proof, the contracting parties do not have incentives to renegotiate at time $\tau_{K}$ (see Lemma 2 in the appendix)

In Section 2 we proceed to characterize the optimal contract. In Section 3, we study how the optimal contract and the resulting equilibrium dynamics depend on the efficiency of financial contract, captured by $\sigma$. In Section 4 , we show that the model can be quantitatively consistent with the observed changes in the failure rate, the volatility of private and public firms, and the age of IPO.

\footnotetext{
${ }^{5}$ In practice, $W_{\hat{\tau}}$ can be implemented by specifying the agent's stake in the firm.
} 


\section{The Optimal Fully Contingent Contract}

In this section we derive the optimal contract in two steps. First, we present and explain the optimal contract after the upgrade, i.e., assuming that investment $K$ has already been made. Next, given the post-upgrade value function, we derive the optimal contract before the upgrade, as well as the optimal timing of the IPO/upgrade.

\subsection{The Optimal Contract after the Upgrade}

Consider the firm after the upgrade. We would like to characterize contracts that maximize the investors' profit for any payoff $W_{0}$ to the agent. That is, the investors' problem is to find a contract $\left(\tau_{L},\left\{C_{t}, t \leq \tau_{L}\right\}\right)$ that maximizes

$$
E\left[\int_{0}^{\tau_{L}} e^{-r t}\left(\bar{\mu}: d t-d C_{t}\right)+e^{-r \tau_{L}} \bar{L}\right]
$$

subject to

$$
W_{0}=E\left[\int_{0}^{\tau_{L}} e^{-\gamma t} d C_{t}+e^{-\gamma \tau_{L}} W_{L}\right], \quad \text { given actions }\left\{\alpha_{\mathrm{t}}=0\right\}
$$

and

$$
W_{0} \geq E\left[\int_{0}^{\tau_{L}} e^{-\gamma t}\left(d C_{t}+\lambda \alpha_{t} d t\right)+e^{-\gamma \tau_{l}} W_{L}\right], \quad \text { given any actions }\left\{\alpha_{\mathrm{t}} \geq 0\right\} .
$$

The theory of dynamic contracts shows that the optimal contract for this problem can be written recursively with the agent's continuation payoff $W_{t}$ as the unique state variable (e.g. see Spear and Srivastava (1987) or Sannikov (2007b)). The agent's continuation value $W_{t}$ is his future expected payoff at time $t$ when he plans to take actions $\alpha_{s}=0$ at all times until termination, i.e.

$$
W_{t}=E_{t}\left[\int_{t}^{\tau_{L}} e^{-\gamma(s-t)} d C_{s}+e^{-\gamma\left(\tau_{L}-t\right)} W_{L}\right], \quad \text { given actions }\left\{\alpha_{\mathrm{s}}=0\right\} .
$$

DeMarzo and Sannikov (2006) derive the optimal contract for a firm without an upgrade option. Here we summarize their characterization:

Proposition 1 (DeMarzo and Sannikov (2006)) In the optimal contract the agent's continuation value $W_{t}$ evolves according to

$$
d W_{t}=\gamma W_{t} d t+\lambda d \Omega_{t}-d C_{t}
$$


starting with value $W_{0}$. When $W_{t} \in\left[W_{L}, W_{C}\right), d C_{t}=0$, and when $W_{t}$ reaches $W_{C}$, payments $d C_{t}$ cause $W_{t}$ to reflect at $W_{C}$. If $W_{0}>W_{C}$, the agent receives an immediate payment of $W_{0}-W_{C}$ at time 0 , and his continuation value drops to $W_{C}$.

The point where the agent consumes $W_{C}$ as well as the principal's profit $\bar{b}(W)$ are determined by the solution of the HJB equation

$$
r \bar{b}(W)=\bar{\mu}+\gamma W \bar{b}^{\prime}(W)+\frac{1}{2} \lambda^{2} \sigma^{2} \bar{b}^{\prime \prime}(W)
$$

on the interval $\left[W_{L}, W_{C}\right]$ with boundary conditions

$$
\bar{b}\left(W_{L}\right)=\bar{L}, \quad \bar{b}^{\prime}\left(W_{C}\right)=-1, \quad \text { and } \quad \bar{b}^{\prime \prime}\left(W_{C}\right)=0 .
$$

The contract is terminated at time $\tau_{L}$ when $W_{t}$ reaches $W_{L}$.

Let us discuss the optimal contract. The law of motion of the agent's continuation value, $W_{t}$, contains two terms related to promise keeping and the agent's incentives. Since $W_{t}$ measures the value that the principal owes to the agent, it must grow at the rate $\gamma$ and decrease with the payments $d C_{t}$. The term $\lambda d \Omega_{t}$ is responsible for the agent's incentives. If the agent reduces effort by $\alpha_{t}$, he benefits immediately at rate $\lambda \alpha_{t}$. At the same time, the signal about the agent's performance $\Omega_{t}$ gets lower at rate $\alpha_{t}$, leading to a reduction in the agent's continuation value at rate $\lambda \alpha_{t}$. We see that in the optimal contract, the agent's incentive constraint is just binding: the agent is indifferent between putting full effort and reducing effort by any amount $\alpha_{t}$. This property of the optimal contract makes sense, since it is costly to give the agent incentives that are too strong.

Second, if $\bar{b}\left(W_{t}\right)$ reflects the principal's profit when the agent's continuation value is $W_{t}$, then

$$
G_{t}=\int_{0}^{t} e^{-r s}\left(\bar{\mu} d s-d C_{s}\right)+e^{-r t} \bar{b}\left(W_{t}\right)=E_{t}\left[\int_{0}^{\tau_{L}} e^{-r s}\left(\bar{\mu} d s-d C_{s}\right)+e^{-r \tau_{L}} \bar{L}\right],
$$

is a martingale. When $W_{t}<W_{C}$, we have $d C_{t}=0$. Then (10) together with Ito's lemma imply that the drift of $G_{t}$ is $e^{-r t}$ times

$$
\bar{\mu}-r \bar{b}\left(W_{t}\right)+\gamma W_{t} \bar{b}^{\prime}\left(W_{t}\right)+\frac{1}{2} \lambda^{2} \sigma^{2} \bar{b}^{\prime \prime}\left(W_{t}\right) .
$$

Thus, equation (11) follows from the condition that the drift of $G_{t}$ must be 0 . 
Regarding the boundary conditions (12), the first one, $\bar{b}\left(W_{L}\right)=\bar{L}$, follows from the fact that the principal's profit is $\bar{L}$ when the contract is terminated. Next, we have $\bar{b}^{\prime}\left(W_{C}\right)=-1$ because the principal's profit translates into the agent's value at one-to-one ratio at the point where the principal pays the agent. Finally, the supercontact condition $\bar{b}^{\prime \prime}\left(W_{C}\right)=0$ comes from the optimal choice of $W_{C}$.

\subsection{The Optimal Contract before the Upgrade}

The optimal contract before the upgrade is also based on the state variable $W_{t}$, the agent's continuation payoff. In the optimal contract this variable follows

$$
d W_{t}=\gamma W_{t} d t+\lambda d \Omega_{t} .
$$

The principal's profit before the upgrade is a concave function that satisfies equation

$$
r b(W)=\mu+\gamma W b^{\prime}(W)+\frac{1}{2} \lambda^{2} \sigma^{2} b^{\prime \prime}(W),
$$

with boundary conditions

$$
b\left(W_{L}\right)=L, \quad b\left(W_{K}\right)=\bar{b}\left(W_{K}\right)-K, \quad \text { and } \quad b^{\prime}\left(W_{K}\right)=\bar{b}^{\prime}\left(W_{K}\right),
$$

where $K$ is the investment required for the upgrade and $W_{K}$ is the agent's value that triggers the upgrade. The smooth pasting condition $b^{\prime}\left(W_{K}\right)=\bar{b}^{\prime}\left(W_{K}\right)$ determines the optimal upgrade point $W_{K}$ to maximize the principal's profit $b\left(W_{K}\right)$. The agent does not receive any compensation before the upgrade because $b^{\prime}(W) \geq b^{\prime}\left(W_{K}\right)>-1$ for all $W \in\left[W_{L}, W_{K}\right]$. Paying a dollar to the agent would result in a gain of value of $-b^{\prime}(W)<1$. A typical form of the principal's profit before and after upgrade is illustrated in Figure 1.

We summarize the principal's profit in the optimal contract for a private firm by the following proposition.

Proposition 2 In the optimal contract for a firm before the upgrade the agent's value follows

$$
d W_{t}=\gamma W_{t} d t+\lambda d \Omega_{t}
$$

until liquidation at the time $\tau_{L}$ when $W_{t}$ reaches $W_{L}$ or a capital upgrade at the time $\tau_{K}$ when $W_{t}$ reaches $W_{K}$, whichever happens sooner. The agent does not receive any compensation until the upgrade. After the upgrade the continuation contract is given by Proposition 1 for the starting value $W_{K}$. 
Proof. See Appendix.

Why is investment of capital $K$ delayed in the optimal contract? Without moral hazard, capital $K$ would be invested immediately to generate a net present value of $(\bar{\mu}-\mu) / r-K>0$. However, due to the agency problem, there is a risk of losing value in case the project is terminated or the manager fired. If $\bar{L}-L<K$, it is inefficient to invest when $W_{t}$ is close to $W_{L}$. Determining the optimal investment time is a real option problem (see Dixit and Pindyck (1994)). It is optimal to invest only when the manager accumulates sufficient promised utility, so that the risk of losing value upon termination is sufficiently small. Unlike in a standard real option setting, however, where the decision to invest is driven by investment opportunities, in our model the optimal investment time is driven by the agency problem.

\section{Theoretical properties}

In this section we show that our model can deliver a number of stylized facts about the age at which firms upgrade and go public (Jovanovic and Rousseau (2001), Fink, Fink, Grullon, and Weston (2005)) and the rate at which private and public firms go out of business (Davis, Haltiwanger, Jarmin, and Miranda (2006)). We focus on the following set of facts:

1. The exit rate of private firms is higher than the exit rate of public firms.

2. Over the past 50 years,

(a) firms have been going public at an earlier age and

(b) the exit rate of private firms has decreased.

Stylized fact 1 is a property of the cross section of firm level risk at any point in time. Stylized facts $2 \mathrm{a}$ and $2 \mathrm{~b}$ reflect the evolution of the US economy over the post-war period.

\subsection{Failure Rates before and after IPOs}

The first lemma shows that the average lifetime of a firm is increasing in the agent's value $W_{0}$. 
Lemma 1 In the model, the value of $E\left[\tau_{L} \mid W_{0}\right]$ does not depend on the current size of the firm (before or after the upgrade) and it is increasing in $W_{0}$.

Proof. Equations (10) and (15) imply that the agent's continuation payoff $W_{t}$ follows the same law

$$
d W_{t}=\gamma W_{t} d t+\lambda \sigma d Z_{t}
$$

with reflection at $W_{C}$ and absorption at 0 both before and after the upgrade. As a result the value of $E\left[\tau_{L} \mid W_{0}\right]$ does not depend on the current size of the firm. Now, consider two values $W_{0}$ and $W_{0}^{\prime}<W_{0}$. Denote by $\tau_{L}$ the time when the process $W_{t}$ hits value $W_{0}^{\prime}$ for the first time. Then

$$
E\left[\tau_{L} \mid W_{0}\right]=E\left[\tau_{L} \mid W_{0}\right]+E\left[\tau_{L} \mid W_{0}^{\prime}\right]>E\left[\tau_{L} \mid W_{0}^{\prime}\right]
$$

QED.

Since the starting value for a private firm $W_{0}$ is always lower than the value $W_{K}$ at which the firm's capital is upgraded, it follows immediately that private firms on average exit more quickly than public firms. This conclusion delivers stylized fact 1 above.

Proposition 3 Private firms on average exit more quickly than public firms.

\subsection{Ex-ante probabilities of IPO and failure}

We now study the trends in failure rates and IPOs, and how they relate to financial development. ${ }^{6}$ We capture the development of financial markets by reductions in $\lambda$ and/or $\sigma$, which capture the severity of the agency problem in our model. Note that the consequences of financial development are not obvious because the optimal contract depends on $\lambda$ and $\sigma$, and we need to understand how the thresholds for failure and for IPO change with these parameters.

Several properties of the model allow us to compare firms' dynamics for different values of $\lambda$ and $\sigma$. One important property is that we can define a normalized continuation value to the agent $w_{t}=W_{t} /(\sigma \lambda)$, whose law of motion does not depend on $\sigma$ or $\lambda$ :

$$
d w_{t}=\gamma w_{t} d t+d Z_{t}
$$

\footnotetext{
${ }^{6}$ Multiple factors certainly explain the historical experience. For instance, IPO firms are younger when market valuations are high (see for example Baker and Wurgler (2006) and the papers discussed there). Here we focus on the long run trend.
} 
The firm goes public and investment $K$ is made when $w_{t}$ reaches $w_{K}=W_{K} /(\sigma \lambda)$. The firm exits when $w_{t}$ reaches $w_{L}=W_{L} /(\sigma \lambda)$.

The following proposition states that $w_{K}$ is uniquely determined by $w_{L}$, independently of $\sigma$ and $\lambda$. Thus, firm dynamics for different values of $\sigma$ and $\lambda$ are fully determined by $w_{0}$ and $w_{L}$.

Proposition 4 For a given value of $w_{L}$, the upgrade point $w_{K}$ does not depend on $\lambda$ or $\sigma$, it increases with $K$, and decreases with $\bar{L}-L$ and $\bar{\mu}-\mu$. Moreover, as $w_{L}$ changes, $d w_{k} / d w_{l} \in(0,1)$.

Proof. The proof of the second part is in the appendix. We include here the proof of the first part because it is simple and informative. The optimal contract is defined by two value functions $b$ and $\bar{b}$ and the endogenous thresholds $W_{C}$ and $W_{K}$, that solve the two differential equations (11) and (13) subject to the two sets of boundary conditions (12) and (14). Define a new function $\Delta(w)$ by

$$
\Delta(w)=\bar{b}(\lambda \sigma w)-b(\lambda \sigma w)
$$

Then, $\Delta$ is the solution to

$$
r \Delta(w)=(\bar{\mu}-\mu)+\gamma w \Delta^{\prime}(w)+\frac{1}{2} \Delta^{\prime \prime}(w)
$$

subject to

$$
\Delta\left(w_{L}\right)=\bar{L}-L, \quad \Delta\left(w_{K}\right)=K, \quad \text { and } \quad \Delta^{\prime}\left(w_{K}\right)=0 .
$$

Therefore neither $\Delta$ nor $w_{K}$ depend directly on $\lambda$ or $\sigma$. We show in the appendix that $d w_{k} / d w_{l} \in(0,1)$. QED.

The following proposition shows that firms are more likely to reach an IPO as financial markets improve.

Proposition 5 Keeping the outside option $W_{L}$ and the starting value $W_{0}$ constant, a decrease in $\lambda \sigma$ leads to:

- a higher ex-ante probability of IPO, 
- a lower ex-ante probability of exit.

Proof. Denote by $w_{L}^{\prime}, w_{t}^{\prime}$ and $w_{K}^{\prime}$ the values of $w_{L}=W_{L} /(\sigma \lambda), w_{t}=W_{t} /(\sigma \lambda)$ and $w_{K}=W_{K} /(\sigma \lambda)$ after a decrease in $\sigma \lambda$. Then $w_{L}<w_{L}^{\prime}, w_{0}-w_{L}<w_{0}^{\prime}-w_{L}^{\prime}$ and the interval $\left[w_{L}, w_{K}\right]$ is longer than $\left[w_{L}^{\prime}, w_{K}^{\prime}\right]$ by Proposition 4. These changes are illustrated in Figure 2 .

Since

$$
d w_{t}=\gamma w_{t}+d Z_{t} \quad \text { and } \quad d w_{t}^{\prime}=\gamma w_{t}^{\prime}+d Z_{t}
$$

it follows that

$$
w_{t}^{\prime}-w_{t}=e^{r t}\left(w_{0}^{\prime}-w_{0}\right) \geq w_{0}^{\prime}-w_{0}>w_{L}^{\prime}-w_{L}
$$

for any path of $Z$. Therefore, it is possible that $w_{t}^{\prime}$ reaches the IPO before exiting while $w_{t}$ exits before reaching the IPO, but not the other way around. That is, any realization of the Brownian motion that leads to an IPO when $\lambda \sigma$ is high also leads to an IPO when $\lambda \sigma$ is low. It is therefore clear that the probability of an IPO increases. QED.

As we see from the proof, a decrease in $\sigma \lambda$ causes these effects in firm dynamics: the starting point $w_{0}$ moves away from the point of exiting $w_{L}$ and closer to the point of IPO $w_{K}$, and the drift towards the point of IPO increases.

\subsection{Ex-post exit rate and average IPO age}

It is important to distinguish the ex-ante probability of failure from the ex-post exit rate, and the ex-ante probability of IPO from the average age of realized IPOs. While it seems intuitive that financial development should lead to a decrease of the average IPO age and a decrease in the exit rate of existing firms, it is not necessarily true.

Consider a decrease in $\lambda \sigma$. All firms that previously reached the IPO threshold now reach it sooner, but some firms that previously exited now also reach the IPO stage. For this latter category of firms, IPOs happen quite late, increasing the average IPO age. For the exit rate, of the firms that exited before the improvement in financial markets, some exit more slowly, while others now reach an IPO. The confounding effect here is that firms that become successful with improved financial markets are the ones that took longer time to exit previously. 
We are able to demonstrate analytically that the exit rate and the average IPO age decrease in the special case where the agent's outside option is $W_{L}=0$. In Section 4, we calibrate the model and we study quantitatively the case where $W_{L}>0$.

When $W_{L}=0$ it follows that $w_{L}=0$ and $w_{K}$ takes the same value both before and after the IPO. As a result, the exit rate and average IPO age depend on the initial value $w_{0}=W_{0} /(\lambda \sigma)$ at which the contract starts. As $w_{0}$ increases, both the IPO age and the exit rate increase, as shown by the following proposition.

Proposition 6 Suppose that $w_{L}=0, w_{K}$ is fixed, and $w_{0}<w_{0}^{\prime}$. Then, starting from $w_{0}^{\prime}$, the exit rate and average IPO age are lower than starting from $w_{0}$.

Proof. The average IPO age starting with $w_{0}$ equals the average age or reaching $w_{0}^{\prime}$ starting from $w_{0}$ plus the average IPO age starting from $w_{0}^{\prime}$. Therefore, firms that reach IPO starting from $w_{0}^{\prime}$ are younger. Denote by $\operatorname{Pr}\left[w_{0} \mid w_{0}^{\prime}\right]$ the probability of reaching starting from $w_{0}^{\prime}$ before reaching the IPO, etc., and by $T\left[w_{0}, w_{K} \mid w_{0}^{\prime}\right]$ the expected time it takes to reach $w_{0}$ or $w_{K}$ starting from $w_{0}^{\prime}$, etc. The exit rate starting from $w_{0}^{\prime}$ is

$\frac{\operatorname{Pr}\left[0 \mid w_{0}^{\prime}\right]}{T\left[0, w_{K} \mid w_{0}^{\prime}\right]}=\frac{\operatorname{Pr}\left[w_{0} \mid w_{0}^{\prime}\right] \operatorname{Pr}\left[0 \mid w_{0}\right]}{T\left[w_{0}, w_{K} \mid w_{0}^{\prime}\right]+\operatorname{Pr}\left[w_{0} \mid w_{0}^{\prime}\right] T\left[0, w_{K} \mid w_{0}\right]}<\frac{\operatorname{Pr}\left[w_{0} \mid w_{0}^{\prime}\right] \operatorname{Pr}\left[0 \mid w_{0}\right]}{\operatorname{Pr}\left[w_{0} \mid w_{0}^{\prime}\right] T\left[0, w_{K} \mid w_{0}\right]}=\frac{\operatorname{Pr}\left[0 \mid w_{0}\right]}{T\left[0, w_{K} \mid w_{0}\right]}$, where $\operatorname{Pr}\left[0 \mid w_{0}\right] / T\left[0, w_{K} \mid w_{0}\right]$ is the exit rate starting from $w_{0}$. Therefore, the exit rate starting from $w_{0}^{\prime}$ is lower. QED.

Of course, $w_{0}$ depends on the division of bargaining powers between the principal and the agent. Proposition 7 shows that $w_{0}$ increases as $\sigma \lambda$ decreases for two extreme cases when the principal has all the bargaining power, and when the agent has all the bargaining power.

Proposition 7 If investors act competitively, then $w_{0}=W_{0} /(\lambda \sigma)$ increases as $\sigma$ decreases. If the investor acts as a monopolist and chooses $W_{0}$ to maximize his profit, then also $w_{0}=$ $W_{0} /(\lambda \sigma)$ increases as $\sigma$ or $\lambda$ decreases.

Proof. See Appendix.

The intuition behind the first part of Proposition 7 is straightforward. The firm becomes more valuable as the agency problem decreases. Since the agent captures all the surplus 
when investors act competitively, it follows that $W_{0}$ increases when $\sigma$ decreases, and a fortiori, so does $w_{0}$. We feel that the assumption of competitive investors is the more one natural in practice, but the second part of the proposition shows that, in any case, our result does not hinge on this assumption.

The intuition behind the second part of Proposition 7 is more subtle. If the investor has all the bargaining power, he does not extract all the value from the agent by setting $w_{0}=w_{L}$ in order to be able to reward and punish the agent. As $\sigma$ decreases, the firm becomes more profitable. As a result, it is in the principal's interest to set $w_{0}$ higher in order to allow the firm to survive for a longer period of time.

\section{Quantitative properties}

In this section, we propose a calibration and we investigate the quantitative properties of the model. We have argued in the introduction that a better understanding of firms' dynamics requires a model that captures agency conflicts as well as large, irreversible investments. The lack of such a model means that the theoretical corporate finance literature has tended to remain qualitative. We do not know, for instance, whether moral hazard causes significant delays in investment and significant increases in business failures, or whether the sensitivity to performance of actual contracts can be explained with plausible amounts of private information. An important advantage of our model is that we can draw on information for many different sources in order to calibrate the structural parameters, and that we can investigate the predictions of the model along many dimensions.

\subsection{Calibration of the parameters}

In our model, the principal and the agent are risk neutral. For the principal, this is without loss of generality. It simply means that the model is written under the risk neutral measure: all cash flows are risk adjusted and discounted at the real risk-free rate, which we set at $r=2 \%$.

For the agent, the issue is more complicated. In reality, entrepreneurs care about idiosyncratic risk. Hall and Woodward (2007) report that this risk is substantial. The expected value of entrepreneurship is $\$ 60,000$ per month, but for an individual with a risk aversion of 1 , the certainty equivalent is around $\$ 13,000$. Entrepreneurs are certainly much less risk 
averse that the median individual. We take the benchmark value to be around $\$ 30,000$ which is half of the expected value. To be consistent, we set $\gamma=2 r=4 \%$. We calibrate the outside option of the manager by looking at the wages of skilled individuals. Philippon and Resheff (2007), for instance, report that engineers with post-graduate degrees earn around $\$ 6,600$ dollar per month in 2001 , while financiers with post-graduate degrees earn about $\$ 10,000$ a month. We set the outside option such that

$$
\frac{W_{L}}{W_{0}}=\frac{1}{3} .
$$

Regarding the starting values, $W_{0}$ and $b\left(W_{0}\right)$, Kaplan and Strömberg (2003) report that founders typically hold $30 \%$ of the cash flow rights in VC contracts. So we set

$$
\frac{W_{0}}{W_{0}+b\left(W_{0}\right)}=0.3 \text {. }
$$

The technological parameters are the profit rates $\mu$ and $\bar{\mu}$, the initial setup cost $I$ and the upgrade cost $K$. We identify $I$ and $K$ with the book values of assets in place before and after the IPO. We could identify $K / I$ either as the growth of the firm around its IPO, or as the difference between the average size of pre-IPO firms and post-IPO firms. For the first measure, Jain and Kini (1994) report industry-adjusted increases of $111 \%$ for capital expenditures around IPOs, which we would translate as $K / I=1.11$. For the second measure, Jain and Kini (1994) report that, in their sample of firms between 1978 and 1988, the median book value of assets pre-IPO is $\$ 14.7$ million. Over the same period, the median book value for Compustat firms in the first 15 years post-IPO is $\$ 38.52$ million, which we would translate as $K / I=1.62$. These two ways to calibrate are not widely different, and we take the average as our benchmark:

$$
\frac{K}{I}=1.36 .
$$

Regarding $\mu$ and $\bar{\mu}$, it is important to realize that we should not calibrate using the average historical profit rates, because this would be inconsistent with our assumption that cash flows are discounted at the risk free rate. Instead, we use Tobin's Q. Jain and Kini (1994) report that a value of $Q$ around 1.5 for firms within 3 years of their IPO. The median Q in Compustat for firms that have been listed for less than 3 years is 1.37 in the 1980s and 1.44 between 1990 and 1998. We take 1.4 to be a representative value. The book value 
post-IPO is $I+K$. The total value of the firm is $W+\bar{b}(W)$. We calibrate Tobin's Q after the IPO as

$$
Q_{K}=\frac{W_{K}+\bar{b}\left(W_{K}\right)}{I+K}=1.4 .
$$

For the relative value of $\bar{\mu} / \mu$, we can use the observed average profit rates, under the plausible assumption that systematic risk is scale-invariant. ${ }^{7}$ Jain and Kini (1994) report that the profit rate drops by roughly $30 \%$ when firms go public. We therefore calibrate

$$
\frac{\bar{\mu}}{I+K}=0.7 \frac{\mu}{I}
$$

Next, we must calibrate the liquidation values. Kim and Weisbach (2007) report that only $20 \%$ of the investment made by VC-backed companies is made of capital expenditures. If we assume that tangible assets and half of non-tangible assets can be recovered, we get a liquidation value of $0.2+0.5^{*} 0.8=0.6$. We therefore set

$$
\frac{L}{I}=\frac{\bar{L}}{I+K}=0.6
$$

Note that the recovery rate is with respect to the book value of assets. It is substantially smaller with respect to the value of the project, since $\mathrm{Q}$ is larger than one.

We normalize $I=1$. There are 8 free parameters: $K, \mu, \bar{\mu}, W_{L}, W_{0}, L, \bar{L}$ and $\lambda \sigma$. We have 7 calibrating equations above. Given a value for $\lambda \sigma$ we can therefore solve the model. What is the range of plausible values for $\lambda \sigma$ ? This depends on our interpretation of the signal $\Omega$. For young ventures, when revenues are either non-existent or very volatile, VCs obtain information about the actions of the entrepreneurs through various means. In our model, we have assumed that the signal to noise ratio does not depend on the scale of the firm. On the one hand, when the firm is young, the VC is very involved and observes a lot of extra information. On the other hand, young firms are intrinsically more volatile. Therefore, it seems to us that the correct starting place is to assume a constant signal to noise ratio. Post-IPO, we use accounting information to calibrate the precision of the signal. We use firms in Compustat that have traded for less than 5 years and we compute firm specific volatilities. The median volatility of revenues (sales) over assets in the post 1980 sample is $13 \%{ }^{8}$ We set $\sigma=13 \%$. The parameter $\lambda$ is less than one. As a benchmark,

\footnotetext{
${ }^{7}$ This would not hold for investments that affect the diversification of firms, but this does not seem to be relevant for IPOs.

${ }^{8}$ The average is $20 \%$ but given the skewness, it seems more sensible to use the median. It is also more conservative because it decreases the importance of moral hazard.
} 
we set the product $\lambda \sigma=10 \%$. We show below that this implies a plausible sensitivity of entrepreneur's wealth to performance, when we compare our optimal contract with actual $\mathrm{VC}$ contracts.

Here is finally the complete set of structural parameters that defines our benchmark calibration:

\begin{tabular}{|l|l|l|l|l|l|l|l|}
\hline$K$ & $\mu$ & $\bar{\mu}$ & $W_{L}$ & $W_{0}$ & $L$ & $\bar{L}$ & $\lambda \sigma$ \\
\hline 1.36 & 0.0532 & 0.0879 & 0.19 & 0.574 & 0.6 & 1.416 & 0.1 \\
\hline
\end{tabular}

With these parameters the model matches the moments described above.

\subsection{Quantitative implications}

In this section, we interpret the predictions of the calibrated model and, when possible, we compare the predictions to their empirical counterparts.

\section{Return to VC}

The setup cost of the project is $I$. The value of the project is $b\left(W_{0}\right)+W_{0}$, and the return to the principal is $b\left(W_{0}\right) / I$. The model predicts a return to the principal of 1.28. We argue that this is a sensible value. The principal in our calibration can be seen as a Venture Capital fund. VC funds have general partners, who choose projects and work with entrepreneurs, and limited partners who provide the money needed for the investments. Hall and Woodward (2007) find that limited partners earn approximately the risk adjusted returns. We can therefore assume that $I$ is paid by outside investors at fair value. Our model therefore predicts that the general partners of the VC funds obtain a return of $28 \%$ on invested capital, which is a payment for the monitoring and advising services provided to the project. This is quantitatively consistent with the available evidence: Hall and Woodward (2007) report VC compensation of $26 \%, 3 \%$ from fees and $23 \%$ from carry. Gompers and Lerner (1999) report a carry of $20.7 \%$.

\section{Sensitivity to performance}

A key prediction of dynamic incentive theory is that the entrepreneur's share should increase when the firm performs well. Kaplan and Strömberg (2003) show that this is also the case in actual contracts. They find that managerial ownership is 6.8 percentage points higher if the management meets all performance and time vesting milestones than if it does not meet any milestone. One way to understand this number is to look at the 
entrepreneur's share just before the firm reaches the IPO threshold relative to its starting value: $W_{K} /\left(W_{K}+b\left(W_{K}\right)\right)-W_{0} /\left(W_{0}+b\left(W_{0}\right)\right)=6.4 \%$. Thus, the model seems to predict a reasonable sensitivity to performance. This can be seen as a check that the parameter $\lambda \sigma$ is correctly calibrated.

\section{IPOs}

What is the quantitative impact of moral hazard on IPOs? We show in the appendix that one can obtain explicit formulas for various observable quantities: probability that a firm will eventually do an IPO, failure rate of pre-IPO firms, age at which firms go public, etc. For instance, the probability that a firm with a current promised value $w$ will eventually go public is:

$$
p(w)=\left(\int_{w_{L}}^{w} e^{-\gamma s^{2}} d s\right) /\left(\int_{w_{L}}^{w_{K}} e^{-\gamma s^{2}} d s\right)
$$

The consequences of moral hazard can therefore be seen in several dimensions.

\begin{tabular}{|l|l|l|}
\hline $\mathrm{Pr}($ No IPO) & Annual failure rate pre-IPO & Median and Mean Age of IPO \\
\hline $12 \%$ & $2.7 \%$ & 2.94 and 3.97 years \\
\hline
\end{tabular}

Recall that in the model without moral hazard, it is never optimal to liquidate and IPOs occur immediately with probability one. Because of moral hazard, $12 \%$ of the firms do not do an IPO. If we consider the population of private firms, the annual failure rate due to moral hazard is $2.7 \%$. This is economically significant since the average annual failure rate of private firms between 1990 and 2001 is $6.78 \%$ in the data of Davis, Haltiwanger, Jarmin, and Miranda (2006).

In the calibrated model, the median age of IPO is 3 years. Empirically, during the last 25 years, the median IPO age is 7 years (Loughran and Ritter (2004)). ${ }^{9}$ Therefore, our model suggests that moral hazard has a significant impact of business failures, as well as the probability and age of IPOs.

\subsection{Financial development and firm dynamics}

Our final task is to study the consequences of financial development on observed firm dynamics. We have calibrated the model using data from recent decades, and we have compared

\footnotetext{
${ }^{9}$ The average is around 15 years, because the extreme skewness of the distribution: many firms go public quickly, while some take a very long time. The distribution implied by the model is also skewed, but not as much as in the data, because we do not include ex-ante heterogeneity.
} 
the predictions of the model for the exit rate and the age of IPO to recent data as well. In earlier decades, however, the exit rate was higher and IPOs took place later in the life cycle of the firm. Jovanovic and Rousseau (2001) and Fink, Fink, Grullon, and Weston (2005) show that the median age of IPO was more than 20 years before 1980, compared to 7 years in the post 1980 sample.

It is more difficult to obtain consistent estimates of the failure rates. The data in Davis, Haltiwanger, Jarmin, and Miranda (2006) cover the whole economy, but are only available from 1977 onward. The average failure rate of privately held firms between 1977 and 1989 is $10 \%$, compared to $6.8 \%$ in recent years. Moskowitz and Vissing-Jorgensen (2002) report a 10 -year survival rate around $34 \%$, which corresponds to a failure rate of $10 \%$. Prior to this date, we could only find data for the manufacturing sector. For instance, Dunne, Roberts, and Samuelson (1989) report (annual) failure rates around 10\% for young manufacturing plants in the 1970s, but the exit rate is lower in manufacturing that in other sectors.

We argue that financial development can account for part of these changes. To show this, we simulate our model for different values of the parameter $\lambda \sigma$

\begin{tabular}{|l|l|l|l|}
\hline & $1-\operatorname{Pr}(\mathrm{IPO})$ & Median Age of IPO & Failure Rate \\
\hline$\lambda \sigma=0.10$ & $12 \%$ & 3 years & $2.7 \%$ \\
\hline$\lambda \sigma=0.15$ & $36 \%$ & 6.3 years & $5.25 \%$ \\
\hline$\lambda \sigma=0.20$ & $71 \%$ & 8.6 years & $14.9 \%$ \\
\hline
\end{tabular}

Financial development can therefore have significant effects on the failure rate and the age of IPO.

To conclude this section, we would like to discuss briefly the issue of firm level volatility. In the model, we did not need to specify the volatility of cash flows because the optimal contract depends only on the sufficient statistic $\Omega$. To be more concrete, assume that the cash flows evolve according to the process

$$
d X_{t}=\left(\tilde{\mu}_{t}-\alpha_{t}\right) d t+d M_{t}
$$

where $M$ is a martingale. The process $M_{t}$ cannot be independent of $Z_{t}$. For instance, we could assume that $M_{t}=Z_{t}+\tilde{M}_{t}$ where $\tilde{M}$ is independent of $Z$. Note that $M$ does not need to be a Brownian motion: it can include discrete jumps. Note also that the volatility of $M$ can vary with the age of the firm. The process $M$ does not appear in the solution 
of the model, since the optimal contract depends only on the sufficient statistic $\Omega_{t}$. We can therefore freely choose the age profile of volatility in order to fit the data. Table 4 in Davis, Haltiwanger, Jarmin, and Miranda (2006) shows that volatility decreases with age, and also that the age-profile of volatility is fairly stable over time: volatility decreases with age roughly in the same way in the 1990s as it did in the 1970s. Moreover, since Fink, Fink, Grullon, and Weston (2005) have shown that the drop in IPO age can account for most of the change in the volatility of public firms, it follows that if we match the trend in IPO age, we can automatically match the trend in volatility, provided that we use the correct empirical age profile of volatility. This is why we focus on the age of IPO and the failure rates, and not directly on the volatilities of cash flows among publicly traded companies.

\section{Concluding Remarks}

We view this paper as making two contributions to the literature. First, we have shown how one can use differential equations to obtain analytical comparative statics in a dynamic moral hazard model with optimal contracting, endogenous exit and investment growth options. Second, we have proposed a complete calibration of the model and we have investigated the quantitative consequences of agency issues. Our results suggest that improvement in financial contracts can explain some of the observed changes in firm dynamics over the past fifty years, in particular the decrease in the rate at which firms go out of business and the decrease in the age at which firms go public. 


\section{A Proof of Proposition 2}

For an arbitrary contract $\left(\left\{C_{t}, t \leq \tau_{L}\right\}, \tau_{L}\right)$, under which the agent's continuation value follows (15), consider the process

$$
G_{t}=\int_{0}^{t} e^{-r s} \mu d s+e^{-r t} b\left(W_{t}\right)
$$

for $t \leq \tau_{L}, \tau_{K}$. Because $b^{\prime}(W)>-1$ for all $W, G_{t}$ jumps down when $C_{t}$ jumps up. Furthermore, when $C_{t}$ is continuous, we have

$$
d G_{t}=e^{-r t}\left(\mu-r b\left(W_{t}\right)+\gamma W_{t} b^{\prime}\left(W_{t}\right)+\beta_{t}^{2} \sigma^{2} b^{\prime \prime}\left(W_{t}\right) / 2-d C_{t}\left(1+b^{\prime}\left(W_{t}\right)\right)\right) d t+\beta_{t} \sigma d Z_{t} .
$$

Because $b$ is also a concave function that satisfies (13), it follows and $G_{t}$ is a supermartingale, and a martingale if and only if $\beta_{t}=\lambda$ and $d C_{t}=0$.

By Proposition 1, the principal's profit at time $\tau_{K}$ is bounded from above by $\bar{b}\left(W_{\tau_{K}}\right) \leq$ $b\left(W_{\tau_{K}}\right)$, with equality only if $W_{\tau_{K}}=W_{K}$. Therefore, the principal's expected profit at time 0 is bounded from above by

$$
E\left[\int_{0}^{\min \left(\tau_{L}, \tau_{K}\right)} e^{-r s} \mu d s+e^{-r \min \left(\tau_{L}, \tau_{K}\right)} b\left(W_{\min \left(\tau_{L}, \tau_{K}\right)}\right)\right]=E\left[G_{\min \left(\tau_{L}, \tau_{K}\right)}\right] \leq G_{0}=b\left(W_{0}\right) .
$$

This bound is attained only for the contract presented in Proposition 2, that is, if $\beta_{t}=\lambda$ and $d C_{t}=0$ until the capital upgrade, which happens when $W_{t}$ hits $W_{K}$, and if the continuation contract is given by Proposition 1 for starting value $W_{K}$ after the capital upgrade. QED

\section{B Implementation with recontracting at time $\tau_{K}$}

We claimed in Section 1.5, that the optimal contract can be implemented just by specifying the agent's compensation $\left\{C_{t}, t \leq \min \left(\tau_{L}, \tau_{K}\right)\right\}$ before the IPO and the agent's payoff $W_{\tau_{K}}$ at the time of the IPO. The following lemma proves this claim:

Lemma 2 Whenever it is optimal to wait to upgrade, rather than to upgrade immediately, the principal and the agent do not have incentives to renegotiate at time $\tau_{K}$.

Proof. There are two cases to consider. If $b^{\prime}\left(W_{K}\right)=\bar{b}^{\prime}\left(W_{K}\right) \leq 0$, the upgrade point $W_{K}$ is on the decreasing portion of $\bar{b}$ and it is not possible for both parties to benefit by renegotiating away from $\left(W_{K}, \bar{b}\left(W_{K}\right)\right)$ to another point on $\bar{b}$. If $b^{\prime}\left(W_{K}\right)=\bar{b}^{\prime}\left(W_{K}\right)>0$, then $b(W)<b\left(W_{K}\right)=\bar{b}\left(W_{K}\right)-K$ on $\left[W_{L}, W_{K}\right)$ because $b$ is a concave function. In this case, it would be optimal to upgrade immediately, and to start the agent with a value $W_{0}>W_{K}$ that maximizes $\bar{b}$. To see why, note that $\bar{b}\left(W_{0}\right)-K>\bar{b}\left(W_{K}\right)-K \geq b(W)$ for all $W \in\left[W_{L}, W_{K}\right]$. QED.

\section{Proof of Proposition 4}

The first part of the proposition is proven in the text. The comparative statics with respect to $K, \bar{L}-L$ and $\bar{\mu}-\mu$ follow from the differential equation and the boundary conditions. We only provide a brief sketch of the proofs here since they are straightforward. For instance, an increase in $\bar{\mu}-\mu$ decreases $\Delta^{\prime \prime}\left(w_{K}\right)$, which makes the function $\Delta$ more concave and 
therefore steeper to the left of $w_{K}$. To make sure that $\Delta\left(w_{L}\right)$ is still equal to $\bar{L}-L$, it is clear that $w_{K}$ must decrease when $\bar{\mu}-\mu$ increases.

Now consider an increase in $w_{L}$ to $w_{L}+v_{l}$, and let us show that this causes $w_{K}$ to increase by $v_{k}<v_{l}$. Denote by $\tilde{\Delta}$ the function that solves equation (16) with boundary conditions

$$
\tilde{\Delta}\left(w_{L}+v_{l}\right)=\bar{L}-L, \quad \tilde{\Delta}\left(w_{K}+v_{k}\right)=K, \quad \text { and } \quad \tilde{\Delta}^{\prime}\left(w_{K}+v_{k}\right)=0,
$$

and let us compare it with the function $\Delta$ that solves (16) with boundary conditions (17). If we show that

$$
\tilde{\Delta}^{\prime}\left(w+v_{k}\right)-\Delta^{\prime}(w)>0
$$

for all $w<w_{K}$, it follows immediately that $v_{l}>v_{k}$. The boundary conditions together with equation (16) imply that the first and second derivatives of $\Delta$ and $\tilde{\Delta}$ match at $w_{K}$ and $w_{K}+v_{k}$ respectively, while

$$
\tilde{\Delta}^{\prime \prime \prime}\left(w_{K}+v_{k}\right)=4 \gamma\left(w_{K}+v_{k}\right)(\bar{\mu}-\mu-r K)>4 \gamma w_{k}(\bar{\mu}-\mu-r K)=\Delta^{\prime \prime \prime}\left(w_{K}\right) .
$$

It follows that (19) holds for $w<w_{K}$ sufficiently close to $w_{K}$. If (19) is ever violated, let $w<w_{K}$ be the largest value where $\tilde{\Delta}^{\prime}\left(w+v_{k}\right)-\Delta^{\prime}(w)=0$. Then, since $\tilde{\Delta}^{\prime}\left(w+v_{k}+\epsilon\right)-$ $\Delta^{\prime}(w+\epsilon)>0$, it follows that $\tilde{\Delta}^{\prime \prime}\left(w+v_{k}\right)-\Delta^{\prime \prime}(w) \geq 0$. At the same time, since (19) holds on $\left(w, w_{K}\right)$, it follows that $\tilde{\Delta}\left(w+v_{k}\right)<\Delta(w)$. But then (16) implies that $\tilde{\Delta}^{\prime \prime}\left(w+v_{k}\right)<\Delta^{\prime \prime}(w)$, a contradiction. QED.

\section{D $\quad$ Proof of Proposition 7}

The proof uses the differential equation

$$
r \bar{g}(w)=\bar{\mu}+\gamma w \bar{g}^{\prime}(w)+\frac{1}{2} \bar{g}^{\prime \prime}(w)
$$

and relies on the following lemma:

Lemma 3 Suppose that a function $g(w ; \phi)$ solves (20) subject to $g^{\prime}(0)=\phi$. Then for all $w>0, g(w ; \phi)$ and $g^{\prime}(w ; \phi)$ increase with $\phi$. Reciprocally if $g\left(w ; \phi^{1}\right)>g\left(w ; \phi^{0}\right)$ for some $w>0$, then: $\phi^{1}>\phi^{0}, g\left(w ; \phi^{1}\right)>g\left(w ; \phi^{0}\right)$ and $g^{\prime}\left(w ; \phi^{1}\right)>g^{\prime}\left(w ; \phi^{0}\right)$ for all $w>0$.

Proof. First of all it is clear that for $w$ small and positive, $g\left(w ; \phi^{1}\right)>g\left(w ; \phi^{0}\right)$ since $g^{\prime}\left(0 ; \phi^{1}\right)>g^{\prime}\left(0 ; \phi^{0}\right)$. If the ranking was reversed for larger values of $w$, the two functions would have to cross. But then they would have two common points, and they would be identical since the space of they are solutions to the same second order equation. Therefore $g\left(w ; \phi^{1}\right)>g\left(w ; \phi^{0}\right)$. Now define

$$
w_{L}=\min \left\{w ; g^{\prime}\left(w ; \phi^{1}\right) \leq g^{\prime}\left(w ; \phi^{0}\right)\right\}
$$

By continuity, $g^{\prime}\left(w_{L} ; \phi^{1}\right)=g^{\prime}\left(w_{L} ; \phi^{0}\right)$. But then, $g^{\prime \prime}\left(w ; \phi^{1}\right)>g^{\prime \prime}\left(w ; \phi^{0}\right)$, and therefore $g^{\prime}\left(w ; \phi^{1}\right)<g^{\prime}\left(w ; \phi^{0}\right)$ at least on a small interval to the left of $w_{L}$. This contradicts the definition of $w_{L}$. Therefore, $g^{\prime}\left(w ; \phi^{1}\right)>g^{\prime}\left(w ; \phi^{0}\right)$ for all $w \geq 0$. The second part of the lemma is easily proved using similar arguments. QED. 
We can now proceed to proving parts one and two of Proposition 7.

If the agent has all the bargaining power, the initial condition is determined by $b\left(W_{0}\right)=$ $I$, where $I$ is the setup cost of the firm, and the condition $b^{\prime}\left(W_{0}\right)<0$. Differentiating the initial condition, we get

$$
\frac{\partial b\left(W_{0}\right)}{\partial \sigma}+\frac{\partial W_{0}}{\partial \sigma} b^{\prime}\left(W_{0}\right)=0
$$

Since $\frac{\partial b\left(W_{0}\right)}{\partial \sigma}<0$ and $b^{\prime}\left(W_{0}\right)<0$, we see that $\frac{\partial W_{0}}{\partial \sigma}<0$.

If the investor has all the bargaining power, then he will choose $W_{0}$ to maximize $b\left(W_{0}\right)$, so $b^{\prime}\left(W_{0}\right)=0$. Define

$$
\bar{g}(w)=\bar{b}(\lambda \sigma w)
$$

Then $\bar{g}(w)$ satisfies equation (20) with boundary conditions

$$
\bar{g}(0)=\bar{L}, \quad \bar{g}^{\prime}\left(w^{c}\right)=-\lambda \sigma, \quad \text { and } \quad \bar{g}^{\prime \prime}\left(w^{c}\right)=0 .
$$

Consider solutions to the equation (20) with a boundary condition $\bar{g}(0)=L$ and various slopes $\bar{g}^{\prime}(0)$. Lemma 3 shows that the slopes $\bar{g}^{\prime}(w)$ are increasing in $\bar{g}^{\prime}(0)$ for all $w$, and so the minimum slope of $\bar{g}$ (at point $w^{c}$ ) is also increasing in $\bar{g}^{\prime}(0)$. See the phase diagram on Figure 3. It follows that as $\sigma$ decreases, $\bar{g}^{\prime}(w)$ increases at all points.

Recall the definition of $\Delta$ from the proof of Proposition 4. Point $w_{0}=W_{0} /(\lambda \sigma)$, the maximum of $b(\lambda \sigma w)=\Delta(w)+\bar{g}(w)$, is determined by the first-order condition

$$
\Delta^{\prime}\left(w_{0}\right)+\bar{g}^{\prime}\left(w_{0}\right)=0 .
$$

Since $\bar{g}^{\prime}\left(w_{0}\right)$ increases as $\sigma$ decreases, it follows that $w_{0}$ also increases. QED

\section{E Closed form expressions for observed quantities}

The dynamics of $w$ are given by

$$
d w_{t}=\gamma w_{t} d t+d Z_{t}
$$

We will use Ito's lemma to obtain the drift of any function $f(w)$ twice continuously differentiable:

$$
d f=\left(\gamma w f^{\prime}+\frac{1}{2} f^{\prime \prime}\right) d t+f^{\prime} d Z
$$

The model imposes restrictions on the drift that lead to differential equations of the form

$$
\gamma w f^{\prime}+\frac{1}{2} f^{\prime \prime}=h(w)
$$

for some function $h($.$) . We shall then use the following lemma repeatedly$

Lemma 4 The solution to equation (22) takes the form

$$
f(w)=f(0)+f^{\prime}(0) \int_{0}^{w} e^{-\gamma z^{2}} d z+2 \int_{0}^{w} e^{-\gamma z^{2}}\left(\int_{0}^{z} h(s) e^{\gamma s^{2}} d s\right) d z
$$

Proof. Multiply both sides of equation (22) by $2 e^{\gamma w^{2}}$

$$
\begin{aligned}
2 \gamma w e^{\gamma w^{2}} f^{\prime}(w)+f^{\prime \prime}(w) e^{\gamma w^{2}} & =2 h(w) e^{\gamma w^{2}} \\
d\left(f^{\prime} e^{\gamma w^{2}}\right) & =2 h(w) e^{\gamma w^{2}}
\end{aligned}
$$




$$
f^{\prime}(w)=e^{-\gamma w^{2}}\left[f^{\prime}(0)+\int_{0}^{w} 2 h(s) e^{\gamma s^{2}} d s\right]
$$

and

$$
f(w)=f(0)+\int_{0}^{w} e^{-\gamma z^{2}} d z\left[f^{\prime}(0)+\int_{0}^{z} 2 h(s) e^{\gamma s^{2}} d s\right]
$$

$Q E D$

\section{E.1 Probability of IPO}

Consider the probability that an IPO occurs, $\operatorname{Pr}\left(\tau_{K}<\tau_{L}\right)=E\left[1_{\tau_{K}<\tau_{L}}\right]$, and define the function $p(w)$ by

$$
p(w) \equiv E_{t}\left[1_{\tau_{K}<\tau_{L}} \mid w_{t}=w\right] .
$$

The drift of $p$ must be zero because it is a martingale. The function $p$ must therefore satisfy the differential equation

$$
\gamma w p^{\prime}(w)+\frac{1}{2} p^{\prime \prime}(w)=0,
$$

with boundary conditions $p\left(w_{L}\right)=0$ and $p\left(w_{K}\right)=1$. Using Lemma 4 , it is easy to see that

$$
p(w)=\left(\int_{w_{L}}^{w} e^{-\gamma s^{2}} d s\right) /\left(\int_{w_{L}}^{w_{K}} e^{-\gamma s^{2}} d s\right) \text { for all } w \in\left[w_{L}, w_{K}\right]
$$

The probability of IPO is increasing and concave.

\section{E.2 Age at IPO}

The average age of firms when they go public is:

$$
E\left[\tau_{K} \mid \tau_{K}<\tau_{L}\right]=\frac{E\left[\tau_{K} \cdot 1_{\tau_{K}<\tau_{L}}\right]}{\operatorname{Pr}\left(\tau_{K}<\tau_{L}\right)}
$$

where $E\left[\tau_{K} \cdot 1_{\tau_{K}<\tau_{L}}\right]$ is a martingale. Define the function $f(w) \equiv E\left[\tau_{K} \cdot 1_{\tau_{K}<\tau_{L}} \mid w_{0}=w\right]$. This function is such that:

$$
E_{t}\left[\tau_{K} \cdot 1_{\tau_{K}<\tau_{L}}\right]=E_{t}\left[\left(\tau_{K}-t\right) \cdot 1_{\tau_{K}<\tau_{L}}\right]+t \cdot E_{t}\left[1_{\tau_{K}<\tau_{L}}\right]=f\left(w_{t}\right)+t \cdot p\left(w_{t}\right) .
$$

The drift of the left hand side is zero, and since the drift of $p$ is also $0, f($.$) must satisfy:$

$$
\gamma w f^{\prime}(w)+\frac{1}{2} f^{\prime \prime}(w)=-p(w)
$$

with boundary conditions $f\left(w_{L}\right)=0$ and $f\left(w_{K}\right)=0$. The solution is:

$$
f(w)=2 p(w) \times \int_{w_{L}}^{w_{K}} e^{-\gamma z^{2}}\left(\int_{w_{L}}^{z} p(s) e^{\gamma s^{2}} d s\right) d z-2 \int_{w_{L}}^{w} e^{-\gamma z^{2}}\left(\int_{w_{L}}^{z} p(s) e^{\gamma s^{2}} d s\right) d z .
$$

The average age of IPO firms is therefore:

$a\left(w_{0}\right)=\frac{f\left(w_{0}\right)}{p\left(w_{0}\right)}=2 \int_{w_{L}}^{w_{K}} e^{-\gamma z^{2}}\left(\int_{w_{L}}^{z} p(s) e^{\gamma s^{2}} d s\right) d z-\frac{2}{p\left(w_{0}\right)} \int_{w_{L}}^{w_{0}} e^{-\gamma z^{2}}\left(\int_{w_{L}}^{z} p(s) e^{\gamma s^{2}} d s\right) d z$. 


\section{E.3 Exit Rate}

Private firms enter at $w_{0}$ and then either go out of business at time $\tau_{L}$ or go public at time $\tau_{K}$. Define the average age of existing private firms

$$
z(w) \equiv E\left[\min \left(\tau_{L}, \tau_{K}\right) \mid w_{0}=w\right] .
$$

Since $E_{t}\left[\min \left(\tau_{L}, \tau_{K}\right) \mid w_{t}=w\right]=z\left(w_{t}\right)+t$ is also a martingale, the function $z($.$) must$ solve

$$
\gamma w z^{\prime}(w)+\frac{1}{2} z^{\prime \prime}(w)+1=0,
$$

with boundary conditions $z\left(w_{L}\right)=0$ and $z\left(w_{K}\right)=0$. The solution is

$$
z(w)=2 p(w) \times \int_{w_{L}}^{w_{K}} e^{-\gamma z^{2}}\left(\int_{w_{L}}^{z} e^{\gamma s^{2}} d s\right) d z-2 \int_{w_{L}}^{w} e^{-\gamma z^{2}}\left(\int_{w_{L}}^{z} e^{\gamma s^{2}} d s\right) d z .
$$

The total exit rate is equal to $1 / z$, but a fraction $p\left(w_{0}\right)$ of the firms go public. Therefore, the rate at which private firms go out of business is

$$
\frac{1-p\left(w_{0}\right)}{z\left(w_{0}\right)}
$$




\section{References}

Admati, A. R., and P. Pfleiderer (1994): "Robust Financial Contracting and the Role of Venture Capitalists," The Journal of Finance, 49(2), 371-402.

Albuquerque, R., and H. A. Hopenhayn (2004): "Optimal Lending Contracts and Firm Dynamics," Review of Economic Studies, 71, 285-315.

Baker, M., and J. Wurgler (2006): "Investor Sentiment and the Cross-Section of Stock Returns," Journal of Finance, 61, 1645-1680.

Biais, B., T. Mariotti, G. Plantin, and J.-C. Rochet (2007): "Optimal Design and Dynamic Pricing of Securities," Review of Economic Studies, 74, 345-390, Working paper, Université de Toulouse.

Caballero, R., and E. Engle (1999): "Explaining Investment Dynamics in U.S. Manufacturing: A Generalized (S,s) Approach," Econometrica, 67, 783-826.

Campbell, J. Y., M. Lettau, B. Malkiel, and Y. Xu (2001): "Have Individual Stocks Become More Volatile? An Empirical Exploration of Idiosyncratic Risk," Journal of Finance, 56(1), 1-43.

Casamatta, C. (2003): "Financing and Advising: Optimal Financial Contracts with Venture Capitalists," The Journal of Finance, 58(5), 2059-2085.

Chemmanur, T. J., and P. Fulghieri (1999): "A Theory of the Going Public Decision," Review of Financial Studies, 12, 249-279.

Clementi, G. L., and H. Hopenhayn (2006): "A Theory of Financing Constraints and Firm Dynamics," Quarterly Journal of Economics, 121, 229-265.

Comin, D., and T. Philippon (2005): "The Rise in Firm-Level Volatility: Causes and Consequences," in Macroeconomics Annual, ed. by M. Gertler, and K. Rogoff. NBER.

Cooley, T., R. Marimon, and V. Quadrini (2004): "Aggregate Consequences of Limited Contract Enforceability," Journal of Political Economy, 112, 817-847.

Davis, S., J. Haltiwanger, R. Jarmin, and J. Miranda (2006): "Volatility and Dispersion in Business Growth Rates: Publicly Traded versus Privately Held Firms," in Macroeconomics Annual, ed. by D. Acemoglu, K. Rogoff, and M. Woodford. NBER.

DeMarzo, P., and M. M. Fishman (2004): "Optimal Long-Term Financial Contracting with Privately Observed Cash Flows," Working Paper, Stanford University.

(2007): "Agency and Optimal Investment Dynamics," Review of Financial Studies, $20,1-151$.

Demarzo, P., M. M. Fishman, Z. He, and N. Wang (2007): "Agency Frictions and Investment Dynamics," Working Paper Kellogg School of Management.

DeMarzo, P., and Y. Sannikov (2006): "Optimal Security Design and Dynamic Capital Structure in a Continuous-Time Agency Model," Journal of Finance, forthcoming.

Dixit, A. K., And R. S. Pindyck (1994): Investment under Uncertainty. Princeton University Press. 
Dunne, T., M. J. Roberts, and L. Samuelson (1989): "The Growth and Failure of U. S. Manufacturing Plants," The Quarterly Journal of Economics, 104, 671-698.

Fink, J., K. Fink, G. Grullon, and J. Weston (2005): "Firm Age and Fluctuations in Idiosyncratic Risk," Working Paper.

Gompers, P., And J. Lerner (1999): "An Analysis of Compensation in the U.S. Venture Capital Partnership," Journal of Financial Economics, 51(1), 3-44.

Hall, R. E., and S. Woodward (2007): "The Incentives to Start New Companies: Evidence from Venture Capital," Working Paper, Stanford University.

Jain, B. A., ANd O. Kini (1994): "The Post-Issue Operating Performance of IPO Firms," The Journal of Finance, 49, 1699-1726.

Jenkinson, T., And A. LuungQvist (2001): Going Public: The Theory and Evidence on How Companies Raise Equity Finance. Oxford University Press, Oxford, UK.

Jovanovic, B., and P. L. Rousseau (2001): "Why Wait? A Century of Life Before IPO," AER paper and proceedings, pp. 336-341.

Kaplan, S. N., And P. Strömberg (2003): "Financial Contracting Theory Meets the Real World: An Analysis of Venture Capital Contracts," Review of Economic Studies, $70,281-315$.

Kim, W., and M. S. Weisbach (2007): "Motivations for Public Equity Offers: An International Perspective," forthcoming in Journal of Financial Economics.

Loughran, T., and J. Ritter (2004): "Why Has IPO Underpricing Changed Over Time?," Financial Management, pp. 5 - 37.

Moskowitz, T. J., And A. Vissing-Jorgensen (2002): "The Return to Entrepreneurial Investment: A Private Equity Puzzle?," American Economic Review, 92(4), 745-778.

Pastor, L., and P. Veronesi (2005): "Rational IPO Waves," Journal of Finance, 60, $1713-1757$.

Philippon, T., And A. Resheff (2007): "Skill Biased Financial Development: Education, Wages and Occupations in the U.S. Financial Sector," Working Paper, New York University.

Piskorski, T., And A. TChistyi (2006): "Optimal Mortgage Design," Working Paper, New York University.

QUADRINI, V. (2004): "Investment and Liquidation in Renegotiation-Proof Contracts with Moral Hazard," Journal of Monetary Economics, 51, 713-751.

Ritter, J. R., And I. Welch (2002): "A Review of IPO Activity, Pricing, and Allocations," Journal of Finance, 57, 1795-1828.

Sannikov, Y. (2007a): "Agency Problems, Screening, and Increasing Credit Lines," Working Paper, NYU.

Paper.

(2007b): "A Continuous-Time Version of the Principal-Agent Problem," Working 
Schmidt, K. M. (2003): "Convertible Securities and Venture Capital Finance," The Journal of Finance, 58(3), 1139-1166.

Spear, S. E., and S. Srivastava (1987): "On Repeated Moral Hazard with Discounting," Review of Economic Studies, 54, 599-617.

Stulz, R. M. (2005): "The Limits of Financial Globalization," Journal of Finance, 60, $1595-1638$. 
Figure 1

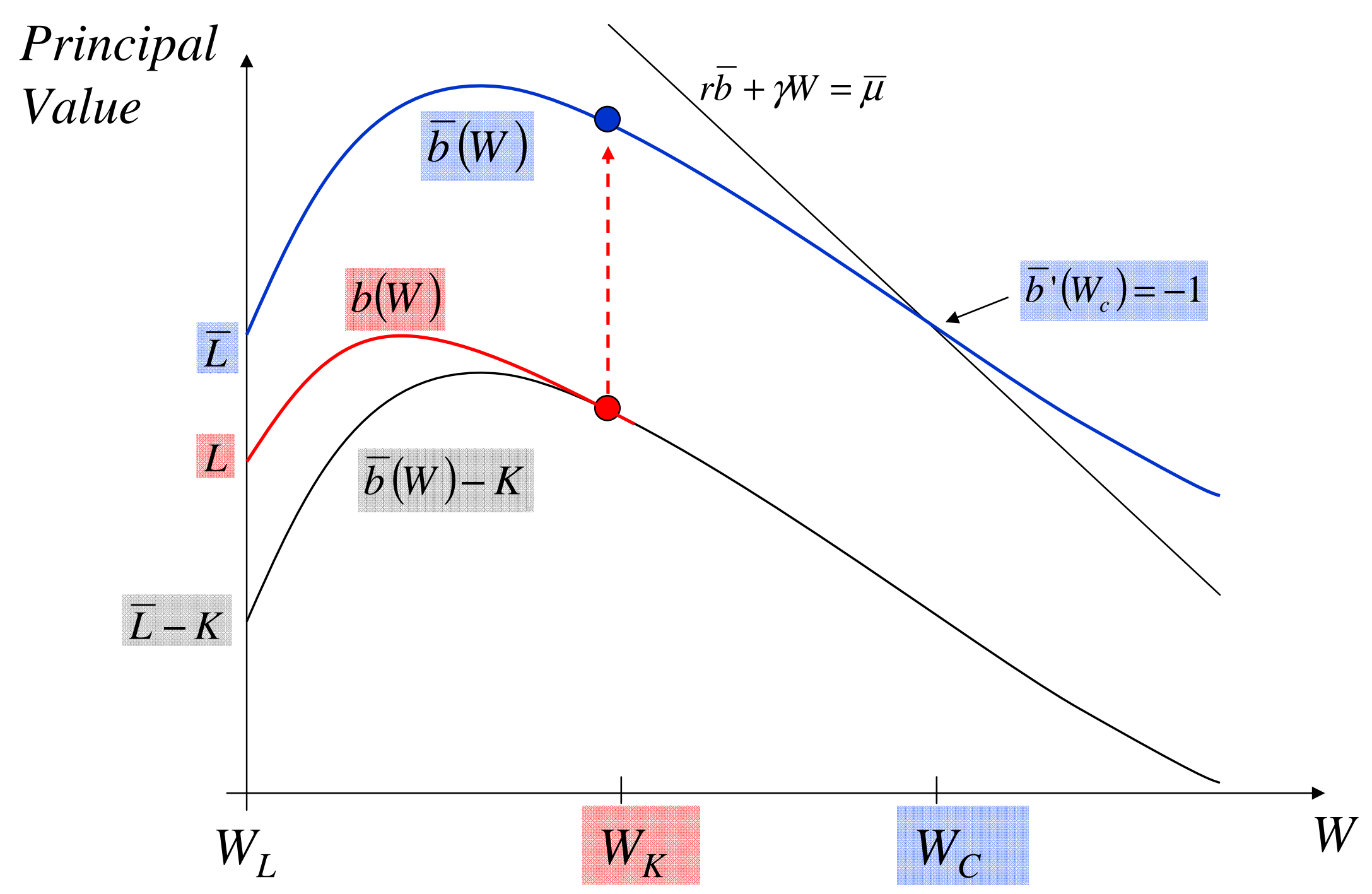


Figure 2

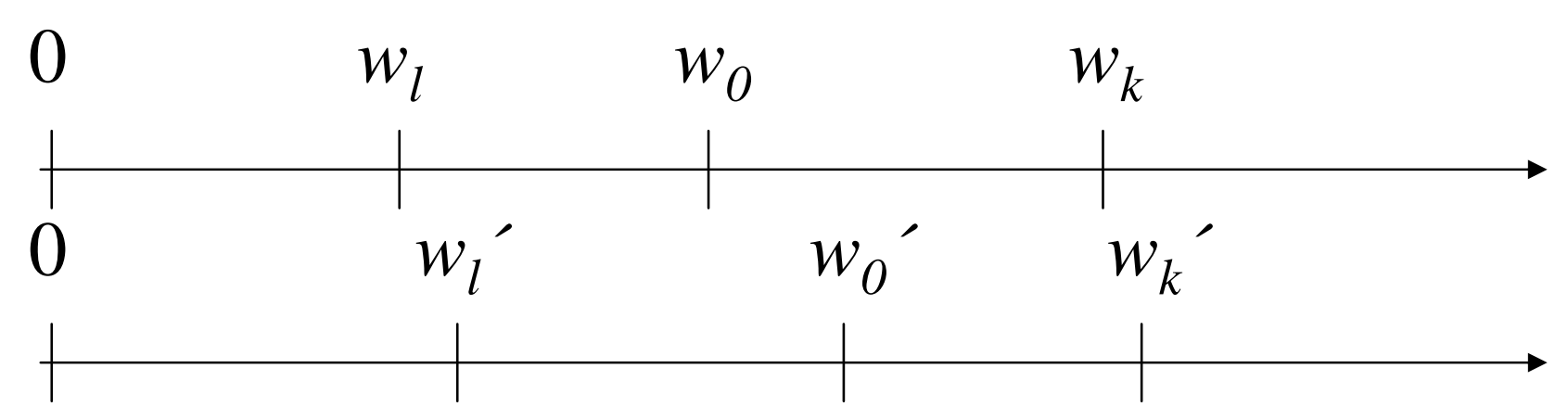


Figure 3

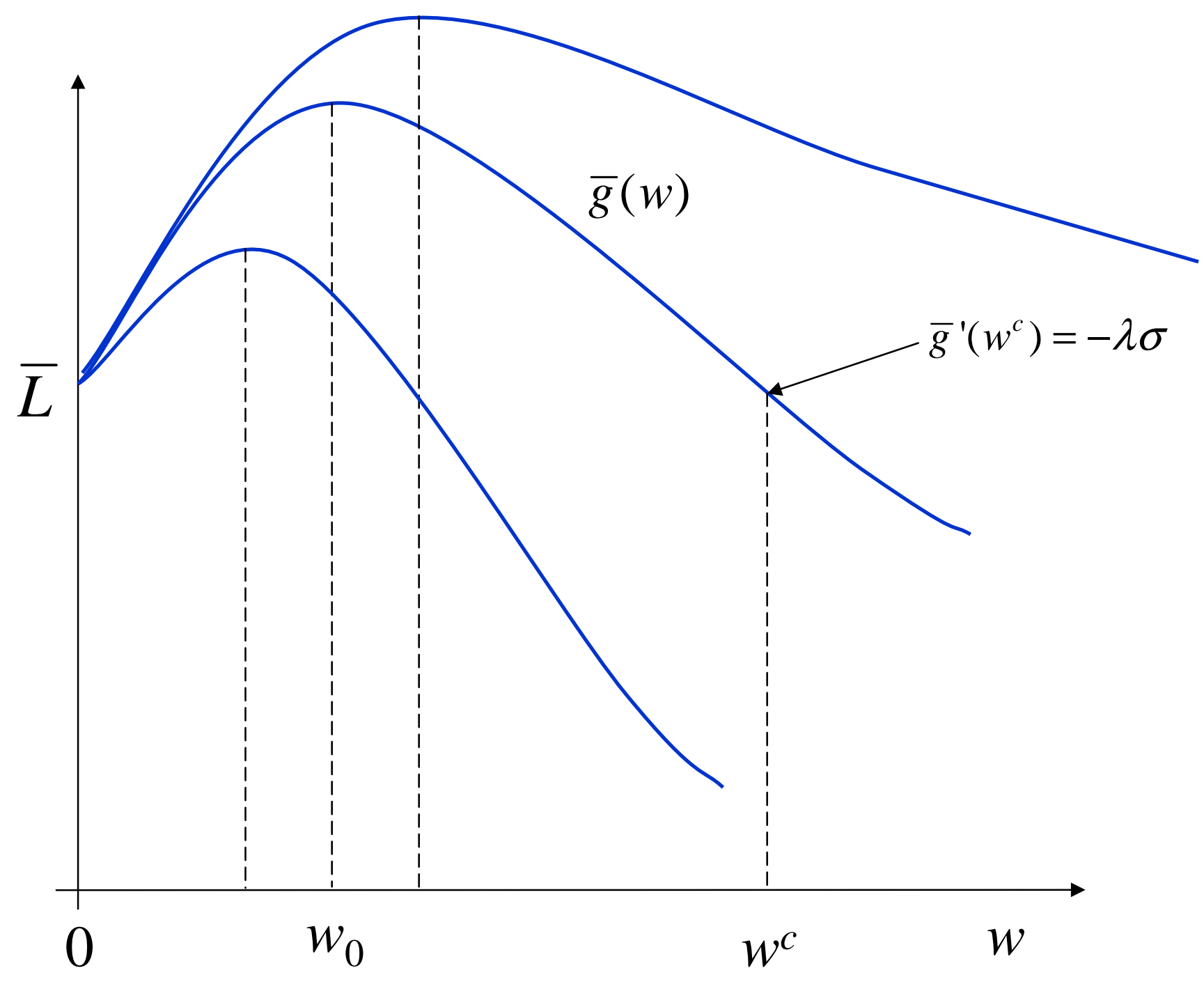

